\title{
DISCIPLINA É LIBERDADE? \\ A PARADOXAL LIBERDADE DO ENSINO REMOTO MEDIADO POR TECNOLOGIAS
}

\author{
Marcos Henrique da Silva Amaral ${ }^{1}$
}

\begin{abstract}
Resumo
O objetivo deste artigo é explicar por que, podendo gozar de liberdade e flexibilidade para organizar suas rotinas de estudo em consonância com seus próprios desejos ao longo da pandemia do novo coronavírus, que lhes colocou sob a égide do ensino remoto mediado por tecnologias, os discentes da educação básica clamam pelo retorno da tutela e da vigilância de uma instituição disciplinar como a escola. Isto em um contexto em que a demanda por mudanças que lhes concedessem precisamente a liberdade de que hoje querem abrir mão tem sido alvo de políticas públicas que redesenham toda a educação básica. Os dados são provenientes de observações sistemáticas a partir da experiência do autor como docente na educação básica em três escolas do Distrito Federal, bem como da aplicação de questionários aos discentes dessas instituições. Os resultados da análise operada a partir de tais dados indicam para a conformação, no molde remoto de ensino, de uma "liberdade paradoxal" que, segundo o filósofo sul-coreano Byung-Chul Han, caracteriza o que chama de sociedade do cansaço. Essa pretensa liberdade acirra um processo de autocobrança, potencializando sentimentos como culpa e inaptidão, e cristaliza um regime atenção caracterizado pelo excesso de estímulos e pela dispersão que, invariavelmente, leva a uma nova percepção a respeito do uso tempo e aos clamores pelo retorno do panoptismo da instituição escolar.
\end{abstract}

Palavras-chave: Sociedade do cansaço. Paradigma do desempenho. Ensino à distância. Saúde mental. Coronavírus.

\section{IS DISCIPLINE THE SAME AS FREEDOM? THE PARADOXAL FREEDOM OF REMOTE EDUCATION MEDIATED BY TECHNOLOGY}

\begin{abstract}
The aim of this paper is to explain why the high school students call for the return of the tutelage and surveillance of a disciplinary institution such as the school, even when they are able to enjoy the freedom and flexibility to organize their study routines in accordance with their own interests and desires throughout the new coronavirus pandemic, which placed them under the aegis of distance learning mediated by technologies. This happens in a context in which the demand for changes that would grant them precisely the freedom they now want to give up has been the target of public policies that redesign the Brazilian education. The paper data come from systematic observations based on the author's experience as high school teacher in three schools in Federal District - one of 27 federative units of Brazil — , as well as survey research among the students at these institutions. The results of the analysis point to the conformation, in distance learning, of a "paradoxical freedom" which, according to the South Korean philosopher Byung-Chul Han, characterizes what he calls the burnout society. This so-called freedom incites a process of self-exploitation, potentiating feelings such as guilt and ineptitude, and crystalizes an economy of attention characterized by excess of stimuli and dispersion which invariably leads to a new perception about the use of time and the clamor for the return of panoptism of the school institution.
\end{abstract}

Keywords: Burnout society. Paradigm of achievement. Distance learning. Mental health. Coronavirus.

1 Doutor em sociologia pela Universidade de Brasília (UnB). Professor da Secretaria de Estado de Educação do Distrito Federal (SEEDF) e pesquisador do grupo Cultura, Memória e Desenvolvimento (CMD/UnB). Email: marcoshenriquesa@gmail.com. http://orcid.org/0000-0002-4655-6050 


\title{
INTRODUÇÃO
}

\begin{abstract}
"Façam uma experiência, deem-nos, por exemplo, mais independência, desamarrem as mãos de qualquer um de nós, ampliem nossa esfera de ação, relaxem a tutela e nós... eu lhes asseguro: nós imediatamente pediremos a volta da tutela”.
\end{abstract}

(Fiódor Dostoiévski) $^{2}$

No dia 11 de março de 2020, o Governo do Distrito Federal decretou a suspensão das aulas em toda a rede de ensino — inclusas escolas públicas e privadas - em decorrência da crise sanitária provocada pela pandemia do novo coronavírus ${ }^{3}$. A medida, em princípio válida por cinco dias, foi prorrogada posteriormente por um período superior a três meses ${ }^{4}$, tempo necessário para o planejamento de estratégias que assegurassem o prosseguimento do ano letivo sem ferir as prescrições profiláticas demandadas pela situação. O imbróglio a respeito do retorno das aulas somente encontrou solução definitiva — ou quase definitiva — na primeira quinzena de julho, quando foram retomadas de forma remota, com auxílio de diferentes tecnologias da informação e da comunicação (TICs), a exemplo do Google Classroom, do moodle e do Google Meet. A solução, em princípio óbvia, uma vez que se apresentava como a única que possibilitava a emulação de algo nos moldes do paradigma educacional vigente, porém mantendo as medidas de isolamento social recomendadas pela Organização Mundial da Saúde (OMS) e pelo Ministério da Saúde brasileiro, suscitou inúmeros debates a respeito da eficácia do formato adotado, principalmente se considerada sua natureza emergencial, bem como acirrou recentes e não tão otimistas prognósticos sobre a educação brasileira, que vieram a culminar no mais recente Plano Nacional de Educação (PNE), em 2014, em mudanças na Lei de Diretrizes e Bases (LDB) da Educação Básica e na consolidação da Base Nacional Comum Curricular $(\mathrm{BNCC})^{5}$.

\footnotetext{
Cf. Dostoévski (2011, p. 115).

Cf. Decreto 40509/2020.

Cf. Decreto 40520/2020; Decreto 40583/2020; Decreto 40817/2020.

5 Cf. Lei 13005/2014; Lei 13415/2017. A respeito dos prognósticos mencionados, me refiro especial aqueles sobre a necessidade de criar um novo modelo educacional que enfatize, antes da retenção de conteúdo, habilidades e competências estimuladas por metodologias cujos cernes são o protagonismo do aluno, a iniciativa e o autodidatismo.
}

\begin{tabular}{|l|l|l|l|l|}
\hline Govista Dialectus & Ano 10 & n. 23 & Maio - Agosto 2021 & p. 231 - 250 \\
\hline
\end{tabular}


Assim, juntamente aos indícios significativos de lacunas no processo de aprendizagem deixadas pelo ensino remoto mediado por tecnologias — as quais de certo merecem um estudo à parte -, se proliferaram e se acirraram discursos que preconizavam a necessidade de autonomia, iniciativa, autodidatismo, senso de responsabilidade e outras qualidades análogas por parte dos discentes, as quais deveriam vir na esteira da significativa liberdade de que gozariam a partir de então para organizar seus estudos. Curiosamente, à medida mesma que a população nacional via suas liberdades mitigadas em razão das providências para contenção do novo vírus, os discentes da educação básica, e especialmente aqueles do ensino médio, exonerados de parte significativa das técnicas disciplinares que caracterizam a instituição escolar, ganhavam uma autonomia sem precedentes para que pudessem organizar o processo de aprendizagem a seu bel-prazer.

No lugar da rigorosa distribuição em salas de aula, não raro exíguas e dotadas de grades em suas janelas — quando da existência destas —, a possibilidade de estudar em quaisquer dos cômodos de sua própria residência ou, quiçá, ao ar livre, em outra cidade ou outro estado. Em substituição às carteiras geometricamente dispostas de modo a evitar o contato contínuo entre dois ou mais indivíduos e refrear potenciais fontes de distração, a oportunidade de estudar "jogado" no sofá, na cama ou no chão. Sem a necessidade do uso de um uniforme que, em última instância, sinaliza para uma tentativa de padronizar os comportamentos no prédio escolar, os discentes vislumbraram ser possível cumprir os estudos sem sequer despiremse de seus pijamas. Sem a coerção ininterrupta possibilitada pelos olhares vigilantes e hierárquicos de câmeras, professores, inspetores e demais instâncias escolares, aquilo que antes poderia soar como o labirinto imutável dos behavioristas parece perder sentido, trazendo à tona inúmeros itinerários, sem que um ou outro ganhe primazia sobre os demais ${ }^{6}$. Na mesma direção, a desregulamentação do tempo de estudo promovida pela ideia de assincronicidade — modelo de interação que, de um lado, pode ocorrer a qualquer momento e, de outro, não pressupõe sincronia entre os interlocutores - advoga ao próprio aluno a função de controlar o ritmo das atividades. Isso tudo ao passo em que o regime de silêncio e retidão corporal que historicamente caracteriza as escolas é substituído pela multiplicação de estímulos sensoriais que passam a competir pela atenção dos discentes - veremos que, não raro, uma das maiores queixas em relação à educação remota é a "falta de foco" ou a "dificuldade para concentrar-se".

6 A reminiscência à imagem do labirinto behaviorista é operada por Zygmunt Bauman (2011, p. 118) para se referir à rotina monótona em que só há um fim a ser descoberto e perseguido a partir de operações básicas de estímulo-resposta, aqui equivalentes às bonificações e sanções do ambiente escolar.

\begin{tabular}{|l|l|l|l|l|}
\hline Revista & Ano 10 & n. 23 & Maio - Agosto 2021 & p. $231-250$ \\
\hline
\end{tabular}


Fazendo referência à análise de Michel Foucault (2014) sobre as instituições disciplinares na magnum opus Vigiar e Punir, diríamos que ficamos diante da desinstitucionalização dos micropoderes escolares cujo objetivo final seria proceder um "bom adestramento" dos corpos e consciências para criar indivíduos úteis, dóceis, treinados para a obediência. E se é verdade que o controle exercido pelas instituições disciplinares se caracteriza, como assevera Foucault, pela abolição dos suplícios corporais e, por consequência, também de sua ostentação pública, é igualmente verdadeiro que a microfísica do poder instaurada por elas não deixa de ser sentida como cerceamento das liberdades individuais em favor de demandas supergóicas estabelecidas pelo contexto. Não por acaso, o sujeito da obediência frequentemente maneja pequenas astúcias - táticas - capazes de tensionar as técnicas disciplinares que lhe são impingidas, ainda que possam aparentar ser indícios do êxito de um sutil processo de adestramento ${ }^{7}$. Estamos nos referindo precisamente ao que Michel Foucault (2014, p. 30) denomina "pontos de lutas e de inversão pelo menos temporária da relação de forças" os quais acabam por desvelar não somente muitas das nuanças do poder disciplinar nem sempre vislumbráveis enquanto formas de controle, mas igualmente suas fissuras internas. No contexto escolar, isso pode ser visto na prática da "cola", nas negociações cotidianas informais que colocam em xeque as hierarquias funcionais e a distribuição temporal das atividades, nas microalterações verificadas nos uniformes - amarras e recortes feitos pelos discentes - , nas troças e dribles que passam ao largo do controle disciplinar, nas reclamações e demonstrações de desinteresse etc.

Não soaria equivocado afirmar, então, que as novas circunstâncias instauradas pela pandemia do novo coronavírus, especialmente no tocante aos múltiplos rearranjos espaçotemporais encetados pelo ensino remoto, acenariam com uma liberdade há muito aspirada pelos estudantes, ilustrada pelas táticas (CERTEAU, 1994, p. 100) que cotidianamente põem em xeque os micropoderes escolares e sentida pelos efeitos desses pontos de luta, como as recentes discussões sobre o ensino domiciliar e a formatação de um "Novo" Ensino Médio, em que ideias como "protagonismo juvenil", "iniciativa", "fazer criativo" e "fazer científico" desconstroem, larga medida, o modelo disciplinar anterior em favor da construção de

7 A este respeito, destaco o diálogo estabelecido por Michel de Certeau (1994) com os postulados Foucault. Na obra A invenção do cotidiano, o autor faz da categoria "tática" para se referir ao reaproveitamento simbólico ou ressignificação de símbolos que, na aparência, podem denotar a aceitação de valores hegemônicos, mas que na realidade representam outros valores e frequentemente possibilitam uma subjetivação idiossincrática em detrimento do ímpeto homogeneizador das técnicas disciplinares: uma engenhosidade para fazer a posição mais fraca parecer mais forte (CERTEAU, 1994, p. 86-90). Assim, as "táticas" seriam uma forma de contrapartida aos micropoderes exercidos pela sociedade disciplinar, porém postas no plano dos sujeitos da obediência.

\begin{tabular}{|l|l|l|l|l|}
\hline Qenista Dialectus & Ano 10 & n. 23 & Maio - Agosto 2021 & p. 231-250 \\
\hline
\end{tabular}


"itinerários formativos" e "projetos de vida" a serem percorridos não como um golpe do destino, mas em consonância com as venetas individuais dos próprios alunos. Em que pese seu caráter emergencial, o ensino remoto aqui observado catalisou, portanto, o atendimento a essas inúmeras e talvez atávicas demandas estudantis, motivo suficiente para que pudéssemos pensar que - em perspectiva comparativa com o ensino presencial - seria bem recebido tanto por discentes como por familiares. No entanto, o que se verificou foi um curioso movimento na direção contrária, com clamores em favor do retorno da tutela disciplinar do prédio escolar, como evidenciam as falas de alguns alunos da rede pública de ensino do Distrito Federal, aqui transcritas a título de exemplificação": "Estudar em casa não é essa maravilha que eu pensava antes, não consigo me concentrar como em sala de aula"; "O ensino presencial é muito melhor mesmo. Nunca achei que falaria isto"; "Não gosto nem um pouco dessa forma como estamos estudando. Eu achei que estudar à distância ia ser muito bom... Mas só trouxe dor de cabeça. 'Tô' me esforçando ao máximo para acompanhar o conteúdo, mas tenho muita dificuldade para aprender sem a pessoa estar na minha frente explicando as coisas"; "Estudar em casa tá sendo mais difícil do que eu pensava. Aprendi muita coisa, inclusive a dar valor à escola"10. Algo semelhante fica evidenciado em levantamento feito junto a alunos de $1^{\mathrm{a}}$ série de ensino médio de uma escola do Distrito Federal, quando 91,4\% disseram sentir falta da rotina na escola $^{11}$.

Como explicar a contemporização da aparente contradição entre demandas por liberdade e o clamor pela tutela de uma instituição disciplinar? Ou seja: como se explica que, gozando de autonomia e flexibilidade para que organizem suas rotinas de acordo com seus próprios desejos, os alunos peçam o retorno do controle espaço-temporal promovido pela escola? Fazendo alusão à obra de Dostoiévski (2011) que nos serve de epígrafe, por que, podendo se abandonar a uma "verdadeira vida viva", longe do que seriam as amarras da sociedade disciplinar, os discentes demonstram uma clara preferência pelas repressões supergóicas de nosso modelo civilizacional? Para responder a este questionamento de forma precisa, seria necessário um minucioso exame das diversas variáveis intervenientes no fenômeno, incluindo as estratégias didático-pedagógicas adotadas pelos professores dos

8 Uma crítica pertinente a essas novas terminologias pode ser encontrada em Demo e Silva (2021).

9 Para fins de organização textual, optou-se pela transcrição das falas dos alunos sempre em itálico ao longo do artigo.

${ }^{10}$ Relatos de alunos do Centro de Ensino Médio Ave Branca (CEMAB), onde o autor do presente trabalho lecionou ao longo do ano letivo de 2020.

11 Levantamento feito em março de 2021, em uma amostra (n) de 152 alunos, que assegurou um erro amostral relativamente tolerável de aproximadamente $6,46 \%$ para a população $(\mathrm{N})$ de 416 alunos da $1^{\mathrm{a}}$ série matriculados no Centro de Ensino Médio 5 de Taguatinga (CEM 5).

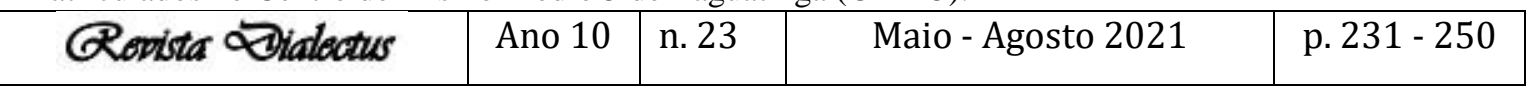


discentes que compõem a amostra analisada. Porém, dado o escopo do presente trabalho, não lograríamos alcançar tamanha exaustividade. $\mathrm{O}$ que se pretende perseguir, doravante, é a hipótese de que essa aparente contradição encontraria explicação no que Byung-Chul Han (2015; 2017a) caracterizaria como uma mudança de paradigmas no exercício do poder. Segundo o prognóstico do filósofo sul-coreano, a sociedade contemporânea - em que a ampliação proeminente dos fluxos informacionais promovidos pelas tecnologias da informação possibilita um acesso progressivamente mais facilitado ao conhecimento e o discurso hiperindividualista e meritocrático que caracteriza o ideário neoliberal se torna um axioma abandona o paradigma "negador" da sociedade disciplinar foucaultiana para priorizar um "esquema positivo de poder", tornando-se uma sociedade de desempenho. Conforme sua definição:

\begin{abstract}
A sociedade disciplinar é uma sociedade da negatividade. É determinada pela negatividade da proibição. O verbo modal negativo que a domina é o não-ter-o-direito. Também ao dever inere uma negatividade, a negatividade da coerção. A sociedade de desempenho vai se desvinculando cada vez mais da negatividade. Justamente a desregulamentação crescente vai abolindo-a. O poder ilimitado é o verbo modal positivo da sociedade de desempenho. O plural coletivo da afirmação Yes, we can expressa exatamente o caráter de positividade da sociedade de desempenho. No lugar de proibição, mandamento ou lei, entram projeto, iniciativa e motivação. A sociedade disciplinar ainda está dominada pelo não. Sua negatividade gera loucos e delinquentes. A sociedade do desempenho, ao contrário, produz depressivos fracassados (HAN, 2015, p. 24-25).
\end{abstract}

Note-se que, na sociedade de desempenho, o que inicialmente se configuraria como liberdade é, em verdade, uma nova forma de coerção cuja origem, antes alheia aos discentes e ilustrada pelo prédio escolar, passa a se situar neles mesmos sob a forma de autocobrança e autoexploração. Esta, por sua vez, é potencializada pelos docentes que, sem a sua tradicional máquina de observar e controlar — o prédio escolar —, difundem a ideia de que, no ensino remoto, o sucesso escolar depende essencialmente dos próprios alunos: "só depende de vocês"; "vocês são capazes"; "vocês precisam correr atrás”; "o seu futuro está em suas mãos”foram algumas das frases mais repetidas pelos professores na ferramenta Google Classroom, adotada pela Secretaria de Educação do Distrito Federal nos anos letivos de 2020 e 2021.

É válido notar que não estamos diante um processo propriamente novo. Conforme mostra Han (2017a), a sociedade do desempenho se conforma à medida que avançam os ditames neoliberais acerca da autoconfiguração, do autoplanejamento e do autoempreendedorismo; algo que precede, em alguns anos ou décadas, a circunscrição temporal analisada por este trabalho e de que a profusão descontrolada de coaches, livros de autoajuda,

\begin{tabular}{|l|l|l|l|l|}
\hline Govista Q Dialectus & Ano 10 & n. 23 & Maio - Agosto 2021 & p. 231 - 250 \\
\hline
\end{tabular}


"selfs" e filtros para editar registros fotográficos nas redes sociais são traços heurísticos ${ }^{12}$. A pandemia do novo coronavírus e suas consequências, como o ensino remoto adotado emergencialmente para mitigar os danos ao processo de aprendizagem, operam essencialmente como catalisadores desse discurso do desempenho, responsável, como propõe Han (2017b, 1. 554, paginação irregular, edição Kindle), pela disseminação de frustração e cansaço generalizados - daí o título de uma de suas mais famosas obras, Sociedade do Cansaço - e enfermidades psíquicas como depressão, burnout, déficit de atenção e hiperatividade.

Assim sendo, a hipótese que sintetiza o percurso deste texto é de que a liberdade aventada pelo ensino remoto não é outra coisa senão uma nova forma de coerção, mas agora interiorizada e, por isso, intensificada, uma vez que se confunde com a positividade e a pretensa liberdade ensejadas pelo verbo poder e pela valorização de qualidades como autonomia, autodidatismo e iniciativa. Conforme sintetiza Han (2017a) na obra Agonia do eros:

(...) o sujeito de desempenho é livre na medida em que não está submisso a outras pessoas que lhe dão ordens e o exploram; mas realmente livre ele não é, pois ele explora a si mesmo (...). O explorado é o mesmo explorador. A gente é vítima e algoz ao mesmo tempo. A autoexploração é muito mais eficiente do que a exploração alheia, pois caminha de mãos dadas com o sentimento de liberdade. (...) O tu podes gera coerções massivas nas quais, via de regra, o sujeito de desempenho se fragmenta. A coerção autogerada lhe parece ser liberdade, de tal modo que ela não é reconhecida como tal. O tu podes exerce inclusive mais coerção do que o tu deves. A autocoerção é muito mais fatal do que a coerção alheia, pois não é possível haver nenhuma resistência contra ela" (HAN, 2017a, p. 13-14, grifos nossos).

Os dados que subsidiam essa hipótese são provenientes de observações sistemáticas a partir da experiência do autor como docente na educação básica em três escolas públicas do Distrito Federal: o Centro de Ensino Médio Ave Branca (CEMAB), o Centro de Ensino Médio 5 (CEM 5), ambos em Taguatinga, e o Centro de Ensino Médio 12 (CEM 12) de Ceilândia. Também foi feita a aplicação de questionários com auxílio da ferramenta Google Formulários — opção justificada pela dispersão espacial da população estudada, pelas condições sanitárias desfavoráveis e pela natureza do tema estudado. Tais dados corroboram para a conformação de uma "liberdade paradoxal" (HAN, 2017b, 1. 1655, paginação irregular, edição Kindle) que, de um lado, (1) acirra um processo de autocobrança, eventualmente convertida em violência simbólica, na medida em que se descola das condições objetivas de possibilidade e

12 É notório que o ponto de encontro entre autores como Anthony Giddens (2002), na obra Modernidade $e$ Identidade, e Ulrich Beck (2011), na obra Sociedade de Risco, é precisamente o arco histórico caracterizado pelo recrudescimento das possibilidades de autoconstrução do indivíduo. Somos não o que somos ou o que fizeram de nós, como no período pré-moderno, mas sim o que fazemos de nós mesmos.

\begin{tabular}{|l|l|l|l|l|}
\hline Qovista Q Dialectus & Ano 10 & n. 23 & Maio - Agosto 2021 & p. 231 - 250 \\
\hline
\end{tabular}


impossibilidade do êxito; e (2) cristaliza um regime de atenção marcado pelo excesso de estímulos que atinge incisivamente a concentração e o foco dos alunos, impedindo que estes façam um uso eficiente do tempo e, por conseguinte, recrudesçam a autoexploração e o sentimento de frustração.

\section{1. "PRECISAMOS CORRER ATRÁS": O ACIRRAMENTO DA AUTOCOBRANÇA}

Em uma de suas 44 cartas do mundo líquido moderno, Zygmunt Bauman (2011, p. 117-121) indica que, na dissolução de uma fase sólida da modernidade — em que noções como ordem, monotonia, regularidade, repetição e previsibilidade são imperativas - em favor do que chama de liquidez, verifica-se uma mudança no modelo de regulação das condutas individuais. Em conclusão semelhante aos diagnósticos de Byung-Chul Han, Bauman indica que, no novo contexto de desregulamentação analisado, a vigilância e o controle invasivo que caracterizam o panoptismo das instituições disciplinares se tornam mais dispendiosos do que o deslocamento da regulação aos próprios subordinados. A fragilização dos vínculos institucionais - como nos casos em que o trabalho e a educação se fazem de forma remota "desloca o ônus da prova, a geração e a manutenção de um arranjo de convivência possível para o outro lado, o do dominado" (BAUMAN, 2011, p. 119).

Assim, cabe aos alunos se comportarem, mesmo à distância, de modo a conquistar a confiança e as graças dos professores; em termos distintos: "venderem" a si mesmos como dignos de estima e reconhecimento. Enquanto no contexto profissional remoto mediado por tecnologias - popularizado como "teletrabalho" ao longo da pandemia do novo coronavírus —, os professores interiorizam uma coerção semelhante em relação aos seus superiores na organização funcional da escola ${ }^{13}$; na interação com os alunos, quase se desobrigam do compromisso da aprendizagem, uma vez que não podem manejar os mesmos micropoderes de que lançavam mão em sala de aula para assegurar um "bom treinamento".

Os efeitos desse novo contexto se sentem, em princípio, na intensificação da vigilância sobre os pais e responsáveis, por meio de instâncias escolares, como os Serviços de Orientação Educacional, e extraescolares, como os Conselhos Tutelares, com o intuito de verificar a continuidade do processo de "treinamento" dos alunos anterior à pandemia que os

13 No contexto do Distrito Federal, isto pode ser visto, por exemplo, no envio semanal ou mensal de relatórios pelos professores para que certifiquem os superiores de suas árduas jornadas de trabalho. Não é necessário somente trabalhar, mas sobretudo prová-lo sistematicamente, o que invariavelmente gera o efeito psicológico da autocoerção e, no limite, do burnout.

\begin{tabular}{|l|l|l|l|l|}
\hline Qovista Q Dialectus & Ano 10 & n. 23 & Maio - Agosto 2021 & p. 231 - 250 \\
\hline
\end{tabular}


confinou em casa. Talvez resida aí, na mediação dessas instâncias, os resquícios do que há propriamente de disciplina — entendida à maneira foucaultiana — no ensino remoto. Seguindo outra direção, rumo à noção de desempenho, os alunos irão internalizar este contexto, tal qual prognosticou Han (2015; 2017a; 2017b), como uma autocobrança com a qual certamente não estão habituados e que talvez tenham dificuldade de nomear enquanto tal. Penso que isto pode ser facilmente inferido a partir da fala da estudante abaixo:

\begin{abstract}
A experiência de estar estudando sozinha em casa 'tá' me fazendo cair na real que se eu não correr atrás, ninguém vai por mim. Vocês [professores] passam as atividades, fazem vídeos para enviar pra gente, aparecem no Meet [ferramenta para interação síncrona por meio de áudio e vídeo] dando aula e tirando nossas dúvidas e se a gente não fizer nada, podemos nos dar muito mal. Não que na escola vocês não passassem conteúdo, mas com o professor alertando ali todo dia que tem dever, trabalho, prova para ser feito, a gente fica em uma zona de conforto muito maior. E por aqui, se a gente não vier olhar atividade por atividade, não tem quem vai estar ali nos alertando.
\end{abstract}

Relatos semelhantes se repetem entre os discentes, indicando a necessidade de terem adquirem um senso de responsabilidade que não tinham antes: "Aprendi que nós precisamos ter interesse e correr atrás para poder aprender" - é um dos vários ecos do que afirmamos acima. Notamos, aqui, que os professores não deixam de cumprir com suas obrigações laborais, mesmo porque estão submetidos ao mesmo processo de acirramento da autocobrança; porém são desonerados pelos discentes da responsabilidade por eventuais lacunas no processo de aprendizagem. Somos "nós", é "a gente" — o alunado — que precisa “correr atrás", "ter interesse".

Verificamos também a autorresponsabilização por eventuais fracassos: o aluno pode se "dar muito mal", caso ele mesmo não consiga provar que dedicou esforços aos estudos. Por fim, na mesma fala, é percebida a associação entre a disciplina escolar — ilustrada pelo "professor alertando todo dia que tem dever" - e a noção de "conforto", exatamente pela mitigação da autocobrança, uma vez que os mecanismos de vigilância aí verificados operam como corresponsáveis na monitoração ora posta sobre os ombros dos discentes. Neste equacionamento das responsabilidades, ou melhor, nesta "mudança topológica da violência" (HAN, 2017b, 1. 74, paginação irregular, edição Kindle), a coerção se livra da negatividade do professor, que poderia penalizar os alunos que não têm o comportamento adequado, para se tornar positivada, psicologizada e autorreferente.

Embora se refira ao contexto laboral, a análise de Bauman (2011, p. 120), abaixo, se adequa de forma ideal ao contexto analisado - mesmo porque a noção de modernidade

\begin{tabular}{|l|l|l|l|l|}
\hline Qovista Dialectus & Ano 10 & n. 23 & Maio - Agosto 2021 & p. $231-250$ \\
\hline
\end{tabular}


líquida por ele forjada pode ser entendida como um modelo de regulação que abrange, em seus efeitos, desde o universo afetivo-pessoal até o profissional, passando pela seara educacional:

(...) cabe aos atuais e futuros empregados "se automonitorarem", serem seus próprios observadores a fim de assegurar que seu desempenho é convincente e aprovável pelos compradores - e que continuará a merecer a aprovação caso estes mudem de desejos, gostos e preferências. Já não compete aos chefes limar e polir as arestas afiadas ou ásperas da personalidade de seus subordinados, nem ocultar suas idiossincrasias, homogeneizar suas condutas ou encarcerar suas ações numa rígida estrutura de rotinas, transformando-os em mercadorias compráveis (...). Não é mais suficiente possuir conhecimentos e habilidades "próprios do cargo" e já demonstrados por outros. (...) É preciso (...), acima de tudo, uma tendência silenciosa e dissimulada a andar com os próprios pés.

Substituamos a palavra "empregados" por alunos, as palavras "compradores" e “chefes" por professores, e chegamos à síntese do argumento desenvolvido a partir da fala dos discentes a respeito do acirramento autocobrança que caracteriza o sujeito de desempenho. Byung-Chul Han $(2015 ; 2017 b)$ estabelece uma relação de quase equivalência entre essa "violência da positividade", do "você pode", do "andar com os próprios pés", que caracteriza a sociedade de desempenho, esta que leva ao aumento progressivo da autocoerção, e a pandemia - esta anterior à do coronavírus — de doenças psíquicas que marcam a sociedade atual. Nas palavras de Han (2017b, 1. 618, paginação irregular, edição Kindle): “O burnout, que muito usualmente precede a depressão, não remete àquele indivíduo soberano do qual brota a força de 'ser senhor de si'. O burnout (...) é a consequência patológica de uma autoexploração voluntária".

Não raro, muitas das queixas dos discentes no período não se direcionam a fatores alheios a si mesmos - como a escola, os professores ou governo —, mas sim a questões psicológicas próprias que denotam a autocobrança: "medo [de que tudo vai dar errado; de falhar; de acumular dever; de não conseguir deixar minha família orgulhosa]", “ansiedade”, "procrastinação", "angústia” — para ficar apenas em poucos exemplos que aparecem quando os alunos respondem espontaneamente sobre sua experiência com o ensino remoto. Uma fala especialmente corrobora esta relação indissociável entre autocobrança e saúde mental no contexto de ensino remoto, pois aponta que, longe de exonerar os discentes da culpa, os distúrbios psicológicos retroalimentam-na e se convertem em mais exploração, com a necessidade de "correr atrás" ainda mais que antes: "eu estive negligenciando as atividades escolares por bastante tempo devido a condições clínicas (ansiedade, ataques de pânico) e 
também por preguiça minha, afinal não posso culpar meus problemas integralmente, mas estou correndo atras da minha recuperação" ${ }^{14}$.

De forma complementar aos textos de Han, poderíamos acionar a análise que Anthony Giddens (2002, p. 39-69) faz a respeito da relação entre segurança ontológica e ansiedade existencial para entender os efeitos psicológicos do ensino remoto. De seu argumento, vale atermo-nos ao fato de que aquilo que, até aqui, temos tratado como sociedade disciplinar, ao estabelecer rotinas cotidianas dotadas de certa regularidade, confere segurança ontológica a amplos segmentos da atividade humana, inclusos aí os estudos. Isto porque "naturalizam" essas rotinas, colocando "entre parênteses uma gama potencialmente quase infinita de possibilidades abertas ao indivíduo" (GIDDENS, 2002, p. 40). Em última instância, a segurança ontológica conferida pela rotina escolar possibilitava que os discentes reprimissem ansiedades inerentes ao próprio ser/estar no mundo - questões como a existência, a morte e a autoidentidade - em favor da continuidade eficiente de atividades como concentrar-se na leitura um texto ou na fala de um professor, estudar para uma prova, preparar-se para um vestibular e aspirar um bom posicionamento no mercado de trabalho.

Pensada à maneira de Giddens, a instituição escolar não constitui apenas uma forma de domínio, como pode deixar transparecer a ideia de disciplina, mas também uma espécie de “casulo protetor" que confere uma confiança básica em relação ao que poderia ser visto como um risco psíquico-emocional ${ }^{15}$. Um exemplo: enquanto submetido ao treinamento escolar, com vistas a pleitos para ingresso no ensino superior, o alunado não vivencia intensamente a angústia da miríade de possibilidades e impossibilidades latentes que poderiam compor outros projetos biográficos. Assim, acresce-se à análise referente ao acirramento do discurso do desempenho, a percepção de que a transposição das atividades escolares para o ambiente doméstico representa a perda de um referencial de segurança ontológica e se torna fonte, portanto, de ansiedades existenciais ou mais precisamente de seu desrecalcamento: "a ansiedade vem com a liberdade" (GIDDENS, 2002, p. 49). Ou, encontrando a interseção entre Giddens (2002) e

${ }^{14}$ Em sondagem realizada entre alunos de $1^{a}$ série do Centro de Ensino Médio 5 de Taguatinga (CEM 5), em março de 2021, foi usada uma escala Likert de 5 pontos para verificar a concordância dos alunos em relação à afirmação "Tenho condições emocionais e psicológicas para enfrentar as dificuldades do momento". $44 \%$ da amostra demonstrou certa aderência à frase, marcando os pontos 4 e 5 da escala. Outros $27,7 \%$ colocaram-se na outra ponta da escala, demonstrando algum nível de discordância ao marcar 1 e 2. 28,3\% marcaram a opção 3 , indicando alguma neutralidade ou indecisão. Considerado o erro amostral de $6,46 \%$, podemos dizer que os três grupos eventualmente se tocam, especialmente se considerarmos que a posição de neutralidade pode significar inclinações circunstanciais a um lado ou outro da mensuração.

15 Embora não caiba nos liames deste texto, vale acessar a teoria da estruturação elaborada por Giddens (2003), em que a estrutura social contemporiza, a um só tempo, "regras" e "recursos", de modo a explicar como a reflexividade atua simultaneamente na reprodução estrutural e em sua modificação, ora adotando os fatores sociais como constrangimentos — quando são sentidos como regras —, ora como possibilitadores.

\begin{tabular}{|l|l|l|l|l|}
\hline Qovista Dialeatus & Ano 10 & n. 23 & Maio - Agosto 2021 & p. $231-250$ \\
\hline
\end{tabular}


Beck (2011, p. 190), diríamos que o ensino remoto revela o que seria a "dimensão do desencantamento" do processo de individualização, antecedida pela sensação de libertação e caracterizada exatamente pela "perda de seguranças tradicionais, com relação a formas sabidas de atuação, crenças e normas de direcionamento". Assim, aquilo que outrora fora posto em parênteses passa a ser confrontado pelo estudante, se tornando uma latente possibilidade de adoecimento psíquico: enfastia-se e aprisiona-se em si mesmo, sem a possibilidade de recorrer às fontes de segurança ontológica anteriores (HAN, 2017b, 1. 586, paginação irregular, edição Kindle).

Até aqui, já temos indícios suficientes para explicar o clamor do alunado pelo retorno às aulas. Porém, vale elencar ainda outros dois motivos pelos quais a já aludida violência da positividade estudada por Han é potencializada e amplificada no contexto da educação pública. (i) Em primeiro lugar, o fato de que o paradigma da negatividade e da proibição que tradicionalmente delineia os contornos da instituição escolar a partir de um sistema de punições/recompensas não estimula o autodidatismo, como salientam os estudantes: "eu nunca tive instrução nenhuma para me tornar uma autodidata da noite pro dia, estou exausta”; "estudar por conta própria é difícil quando não se tem uma boa base para isto". Os discentes não adquirem, ao longo de sua socialização, disposições para usar a autonomia para a organização dos estudos que o ensino remoto mediado por tecnologia lhes impôs. Nós todos nos desacostumamos da vida (...) ao ponto de sentirmos às vezes uma certa repugnância pela verdadeira vida" - dirá o homem subterrâneo de Dostoiévski (2011, p. 114), para se referir ao fato de não sabermos lidar com uma existência sem repressões. Ou ainda, usando os termos caros à obra de Byung-Chul Han: enquanto as circunstâncias pendem a um "esquema positivo de poder", em que qualidades como "projeto", "iniciativa" e "motivação" são imperativas; os alunos mantêm-se apegados a um paradigma "negador" - que encontra antecedentes na educação a base de palmatória e é reatualizado cotidianamente pelos dispositivos de vigilância do ambiente escolar. Em um segundo relato, o sentimento de não adequação é seguido, como em outros casos, pela amplificação da autocoerção, ainda que o problema referente à internalização de pré-disposições para agir, como o autodidatismo aqui analisado, seja eminentemente social como Pierre Bourdieu (1996; 2008) demonstrará exaustivamente ao longo de sua obra:

É muito dificil 'pra' mim esse negócio de aula online, anotar e estudar tudo por conta própria. Eu nunca tive esse costume, até porque acho que nunca precisei realmente ter, a não ser que fosse estudar 'pra' prova. Mas agora é diferente e 'tá' dificil 'pra' mim. Acho que não só 'pra' mim. Talvez seja só a minha preguiça; que eu preciso muito me esforçar mais.

\begin{tabular}{|c|c|c|c|c|}
\hline Qevista Dialectus & Ano 10 & n. 23 & Maio - Agosto 2021 & p. $231-250$ \\
\hline
\end{tabular}


(ii) Em segundo lugar, e em complementaridade ao apontamento acima, a sacralização do êxito individual encetada pela sociedade de desempenho desconsidera as condições objetivas - materiais e simbólicas — de tal êxito. Em circunstâncias normais, diante de impossibilidades objetivas que com frequência se impõem aos alunos de escolas públicas brasileira, o discurso do mérito já soaria como uma "brutalidade psicológica", uma violência simbólica, porque, mostrará Pierre Bourdieu (1996, p. 46), vela as assimetrias na distribuição de capital econômico e capital simbólico entre os discentes em favor da ideia de que todos estão em uma competição justa, em igualdade de condições, para se construírem enquanto indivíduos exitosos. Quando fala de capital simbólico, o autor francês está fazendo referência ao gosto pela leitura e por certos gêneros musicais, a formas de falar, ao acesso facilitado a bibliotecas, teatros, cinemas e museus, a posturas corporais, a conhecimentos de informática, a hábitos de estudo, a pré-disposições para se concentrar, escrever, pesquisar, dentre outras internalizadas no bojo familiar - entra aqui, como se pode perceber, práticas vinculadas àquele autodidatismo de cuja falta os alunos mostram-se queixosos.

A reprodução do discurso acerca da igualdade do sistema educacional, bem como da possibilidade universal de construção de si mesmo - "você só depende de seu esforço, de seu talento" - , desconsidera tais assimetrias, fazendo com que parte significativa dos alunos, especialmente no contexto das escolas públicas, passe a se considerar intelectualmente inferior aos demais segmentos do alunado e aceite que são eles, em vez do sistema educacional e dos desafios estruturais impostos, que têm culpa por seu fracasso, adentrando em processo de crise psíquica e adoecimento mental. Conforme concluem Penso e Sena (2020), o contexto cultural e econômico dos jovens cumprem um importante papel na formatação de sua desesperança e das consequências dessa desesperança, como o suicídio:

(...) os jovens que vivem em contextos de pobreza e vulnerabilidade (...) veem-se aprisionados em situações vinculados à falta de oportunidades e carências, fazendo com que seus sonhos sejam boicotados ou adormecidos e seus planos pessoais sem possibilidade de realização (PENSO; SENA, 2020, p. 69).

É óbvio que tais assimetrias antecedem (e muito) o momento desta análise e, portanto, o ensino remoto emergencial. Entretanto, como demonstrará o sociólogo português Boaventura de Sousa Santos (2020), a pandemia do novo coronavírus delineia um novo espaçotempo de natureza sociocultural, o qual denomina "sul da quarentena", caracterizado exatamente pelo acirramento de vulnerabilidades que precedem a pandemia: "a quarentena não só torna mais visíveis, como reforça a injustiça, a discriminação, a exclusão social e o sofrimento imerecido que elas provocam" (SANTOS, 2020, p. 21). Além da já aludida 
inaptidão para o autodidatismo, a qual provavelmente compartilham com os discentes da rede privada ou pelo menos com parte deles, os alunos de escola pública podem sentir a violência da positividade amplificada exatamente porque o "ideal de ego" — ou "eu ideal"16 — resultante de uma sociedade do desempenho se torna ainda mais irrealizável em razão de sua situação de vulnerabilidade, conforme demonstram os relatos dos docentes: "Nem todos os alunos estão em situação de igualdade nessa pandemia. Eu, por exemplo, não tenho computador e nem notebook, tenho apenas meu celular, a tela é pequena e isso dificulta acompanhar as atividades. Alguns alunos, nem celular têm e podem reprovar injustamente"; "Colocaram a gente em uma competição, mas se não ganharmos, o que acontece? ”.

Nestes casos, o eu ideal e o eu real se comportam como vetores de mesma direção, porém em sentidos opostos: uma disputa incessante entre devir e ser cujo resultado final só pode ser os sentimentos de culpa, fracasso pessoal, medo e paralisia ante o real, conforme demonstra exaustivamente Byung-Chul Han (2017, 1. 661, paginação irregular, edição Kindle):

\begin{abstract}
Na transição da sociedade de disciplina para a sociedade de desempenho, o superego positiva-se para o ego ideal. O superego é depressivo, proferindo sobretudo proibições. Com "o traço rigoroso e cruel do dever que dita ordens", com o "caráter das restrições rígidas, das proibições cruéis", ele domina o ego. O sujeito de desempenho projeta-se na direção do eu ideal, enquanto o sujeito da obediência submete-se ao superego. Submissão e projeção são dois modos de existência distintos. Do superego surge uma coerção negativa; já o eu ideal, ao contrário, exerce uma coerção positiva sobre o ego. A negatividade do superego restringe a liberdade do ego, mas o projetar-se para o eu ideal, ao contrário, é visto como um ato de liberdade. Em vista do fato de que o eu ideal se torna inalcançável, ele se considera deficitário, fracassado, sobrecarregado com suas autorreprimendas. A partir do fosso que se abre entre o eu real e o eu ideal, desenvolve-se uma autoagressividade crescente (grifo nosso).
\end{abstract}

\title{
2. "ME DESCONCENTRO COM COISAS INÚTEIS": UM NOVO REGIME DE ATENÇÃO E A FALTA DE FOCO
}

Uma das reclamações mais comuns entre os discentes em relação à educação remota é o tempo, a falta dele ou a dificuldade em organizá-lo: "o que mais me incomodou foi a falta de tempo que eu tive para realizar as atividades"; "a minha maior dificuldade é o tempo"; "tenho pouco tempo para estudar"; "meu tempo é limitado”. Curiosamente, a multiplicação dos relatos queixosos sobre o tempo vem acompanhada da constatação de que, a

16 Entende-se como "ideal de ego" ou "eu ideal” — duas traduções possíveis para o ideal-ich freudiano — a instância da personalidade resultante de modelos morais e estéticos coletivos. Em última instância, o "ideal de ego" é o conjunto de aspirações construídas a partir do que o sujeito supõe que se espera dele, que soam cada vez mais inatingíveis conforme avançam os ditames positivadores da sociedade do desempenho (SILVA, 2007).

\begin{tabular}{|l|l|l|l|l|}
\hline Rovista Dialectus & Ano 10 & n. 23 & Maio - Agosto 2021 & p. 231 - 250 \\
\hline
\end{tabular}


rigor, os alunos têm dedicado menos horas às atividades escolares do que se dedicavam na modalidade presencial de ensino, conforme mostra o Figura 1, logo abaixo. Antes das medidas de isolamento social decorrentes da pandemia do novo coronavírus e, portanto, antes das legislações que suspenderam as aulas nos prédios escolares, os alunos que compõem a amostra dedicavam ao menos cinco horas aos estudos - o tempo equivalente às aulas de que participavam presencialmente. Remotamente, estudando em casa, 75\% dos estudantes inquiridos dedicam no máximo duas horas para cumprir suas atividades escolares - menos tempo, inclusive, que o sugerido pela Recomendação 1/2020 do Conselho de Educação do Distrito Federal (CEDF) para os alunos de ensino médio ${ }^{17}$. Somente $6,6 \%$ da amostra se aproximam, de alguma forma, do regime temporal anterior à pandemia.

FIGURA 1 - A organização temporal dos estudos na educação remota segundo os alunos ${ }^{18}$

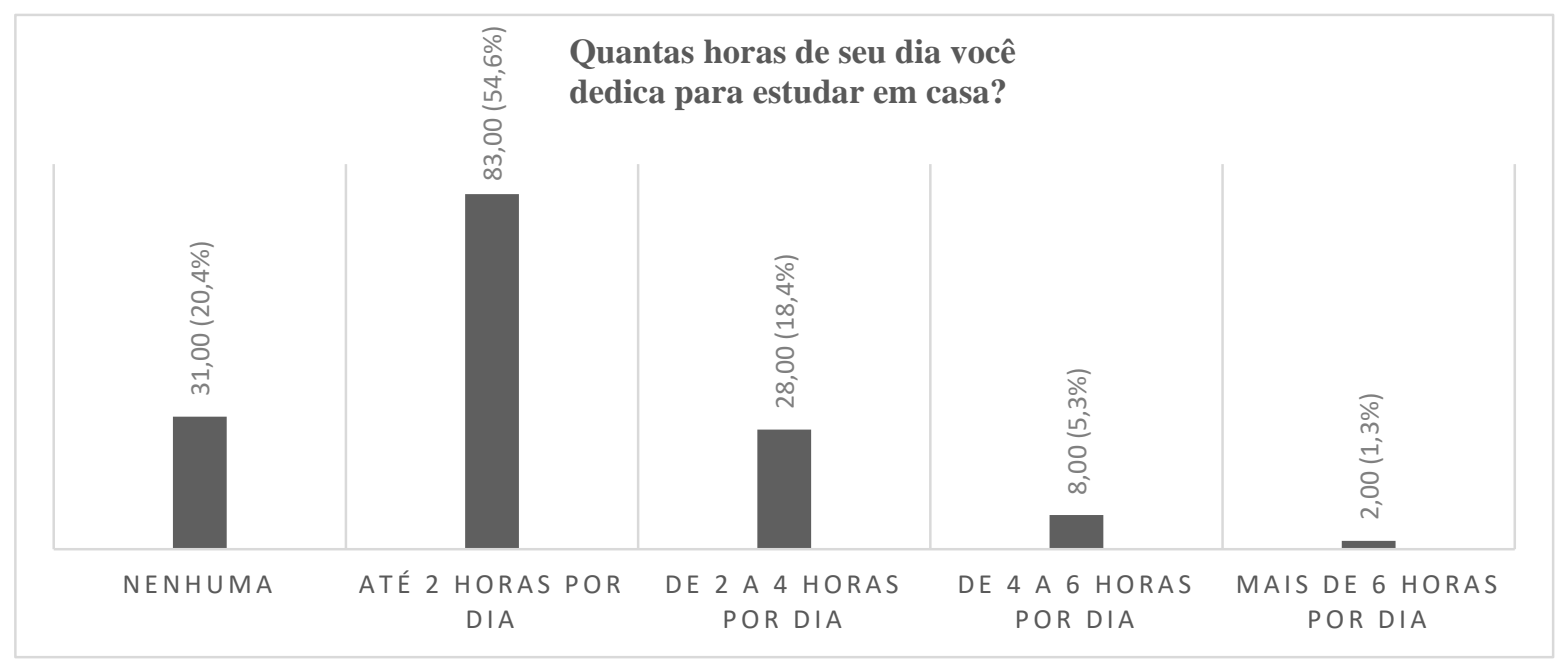

Como explicar então que, dedicando menos horas aos estudos, os alunos reclamem que a falta de tempo seja um dos maiores empecilhos para a eficácia de seu aprendizado de forma remota? Uma possível resposta estaria no fato de que alguns alunos se viram na necessidade de conciliar os estudos com o trabalho - quase sempre em regime informal e de horários flexíveis - para complementar a renda familiar, fortemente afetada pela crise econômica que veio na esteira da sanitária. Os dados coletados a este respeito junto à mesma amostra não possibilitariam, no entanto, sustentar tal explanação, uma vez que somente $13,8 \%$ afirmam conciliar estudo e trabalho. Assim sendo, resta-nos relativizar a concepção de tempo,

17 Segundo a Recomendação, para alunos de $6^{\circ}$ a $9^{\circ}$ ano do ensino fundamental e para os de ensino médio, as "atividades escolares não devem ultrapassar 3 (três) horas diárias diante da "tela", assim como não devem representar estresse adicional no ambiente familiar".

18 Dados referentes a uma amostra de alunos da $1^{\mathrm{a}}$ série do Centro de Ensino Médio 5 de Taguatinga (CEM 5) com erro amostral de $6,46 \%$.

\begin{tabular}{|l|l|l|l|l|}
\hline Govista & Ano 10 & n. 23 & Maio - Agosto 2021 & p. 231 - 250 \\
\hline
\end{tabular}


tal qual o faz Hans Castorp, protagonista d’A Montanha Mágica de Thomas Mann: “O tempo não tem natureza própria, em absoluto. Quando nos parece longo, é longo, e quando nos parece curto, é curto" (MANN, 1. 1420, paginação irregular, edição Kindle). Em que pese o caráter eminentemente literário e ficcional da obra, a construção de Mann nos direciona precisamente ao problema que se ergue diante de nós: ao reclamar da "falta de tempo", o que os alunos trazem à tona é que a ausência da instância disciplinar capaz de uma elaboração temporal das atividades a serem realizadas leva a uma reconfiguração da percepção do tempo — talvez uma "aceleração" ou "diluição" do tempo, a ponto de torná-lo um quase nada, porque o aluno perde a habilidade, antes forjada à base dos micropoderes representados pelo olhar dos professores, de contemplar atentamente o que tem diante de si, o que significa, por óbvio, a impossibilidade de emular algo nos moldes da educação escolar que tinha.

Tal reconfiguração, dirá Han (2015), é antes de tudo o efeito do excesso de estímulos, informações e impulsos, que constituem também a noção de positividade. Aliás, os relatos acerca do excesso de fontes de distração e do "mau uso do tempo" talvez sejam um dos mais recorrentes entre os discentes: "sempre arranjo uma distração para não fazer os deveres; aí quando eu lembro já 'tá' de noite”; “minhas dificuldades estão em manter o foco nos estudos; eu perco o foco muito fácil; qualquer barulho, movimento, me faz perder o foco"; "uma das maiores dificuldades de estudar em casa é a concentração, porque existem diversos fatores que podem tirar a nossa concentração"; " a experiência de estudar em casa é ruim 'pra' mim, pois eu fico toda hora rindo e me desconcentrando com coisas inúteis”; “quando se estuda em casa sempre tem uma coisa te distraindo e o uso do celular também ajuda muito nessa distração”; "nessa pandemia, tem ficado muito difícil estudar com tantas distrações como o celular, videogame, televisão etc.".

Talvez uma das maiores contribuições de Byung-Chul Han para a compreensão das sociedades contemporâneas diz respeito exatamente a um novo regime de atenção que vem na esteira do excesso de estímulos e das cobranças por manter-se "antenado" a respeito de todos os assuntos: é necessário estar por dentro das últimas fofocas, do reality show da moda, das últimas tendências, do noticiário político, de todas as séries e filmes que pululam em cada vez mais numerosas plataformas de streaming e ainda cair na graça de professores e patrões a partir de uma "venda" bem sucedida de si mesmo.

A bem da verdade, a preocupação com os efeitos psíquicos do excesso de estímulos não é algo novo. Antecedendo Han em ao menos um século, Georg Simmel (1967) forja o termo "atitude blasé" para aludir às implicações do acirramento das forças externas da metrópole o ritmo acelerado, os estímulos sensoriais, o excesso de informações, a impessoalidade e

\begin{tabular}{|c|c|c|c|c|}
\hline Qovista Dialectus & Ano 10 & n. 23 & Maio - Agosto 2021 & p. $231-250$ \\
\hline
\end{tabular}


efemeridade das trocas simbólicas — sobre as personalidades individuais. Sob o impacto da urbe, dirá Simmel, o indivíduo se fecha em si mesmo, adotando um ar de indiferença ou até aversão em relação ao mundo exterior, para proteger aquilo que constitui suas idiossincrasias. Embora haja um ponto de tangência entre ambas a reflexões, especialmente no que se refere ao objeto de interesse dos pesquisadores, Han parece atualizar o argumento de Simmel na medida em que, no contexto do desempenho, especialmente neste início do século XXI, já não se nota propriamente um ímpeto de defesa em relação ao excesso de estímulos, mas, ao contrário, uma abertura quase irrestrita às diversas fontes de atenção, de tal sorte que soa completamente plausível a hipótese segundo a qual o que se trata por déficit de atenção e hiperatividade, além de novas patologias psicológicas, como a síndrome de FoMO — fear of missing out —, caracteriza uma nova normalidade, um novo regime de atenção. Enquanto a "atitude blasé" cunhada por Simmel faz referência a um modelo imunológico que reconhece e repele o exterior como ameaça; a formatação dessa nova economia da atenção incide diretamente sobre o sistema neuronal-psíquico, porque a positividade não é identificada como um corpo estranho, mas como parte constitutiva do ideal de eu no paradigma do desempenho (HAN, 2017).

Deixe-se claro que Han não trata isso como um progresso civilizatório; vê, antes, como a degradação do que chama de "vida contemplativa" em favor da "vita activa", quando se torna um joguete do burburinho das modas, circunstâncias, conjunturas e consumos (HAN, 2015). O novo regime caracterizado por uma "atenção multitasking" fragmenta e destrói a atenção, conforme sumariza:

Essa atenção dispersa se caracteriza por uma rápida mudança de foco entre diversas atividades, fontes informativas e processos. E visto que ele tem uma tolerância bem pequena para o tédio, também não admite aquele tédio profundo que não deixa de ser importante para um processo criativo. (...) O tédio profundo constitui o ponto alto do descanso espiritual. Pura inquietação não gera nada de novo. Reproduz e acelera o já existente (HAN, 2015, p. 33-34).

A partir desta análise, é possível propor que a reclamação acerca da falta de tempo feita pelos alunos é, em verdade, o indício da angústia gerada por esta atenção dispersa, que lhes causa a sensação de "tempo desperdiçado" ou "pouco tempo" — isso porque a multiplicação e dispersão de focos de atenção simultâneos extrapolam qualquer economia da utilidade. Ou como relatou uma aluna, as distrações lhe arroubam de tal maneira que, quando percebe, "já 'tá' de noite" e os "deveres" não foram feitos. Por isso, a demanda pelo retorno da tutela disciplinar da escola está diretamente relacionada à necessidade de controle espaçotemporal das atividades. Não é um acaso que Foucault conceda alguma primazia a essas

\begin{tabular}{|l|l|l|l|l|}
\hline Qonista & Ano 10 & n. 23 & Maio - Agosto 2021 & p. 231 - 250 \\
\hline
\end{tabular}


categorias em sua análise das instituições disciplinares: é necessário poder localizar o sujeito da obediência no espaço, estabelecer presenças e ausências, vigiar o comportamento discente a cada instante — daí a ideia do panóptico — elaborar e dividir a rotina de atividades para assegurar a qualidade do tempo empregado, anulando qualquer possível fonte de distração.

Da retroalimentação da autocobrança e da frustração pela incapacidade de concentrar-se e organizar-se espaço-temporalmente, vem o reconhecimento da importância ou ao menos da sensação de comodidade — de segurança ontológica, talvez — ensejada pelo espaço físico da escola e da vigilância operada pelos professores: "seria muito melhor dentro da sala de aula, com meus amigos e o meu professor"; "na escola, fico mais concentrada"; "sempre fui muito apegada a um professor, ali na minha frente”; "confesso que preferia mil vezes aulas presenciais do que remotas. [Ensino remoto] cansa muito, é bem mais cansativo do que você estar em uma escola, sentado em uma cadeira". O clamor, neste caso, é claro: é pelo retorno precisamente do que Foucault chama de disciplinas, os "métodos que permitem o controle minucioso das operações do corpo, que realizam a sujeição constante de suas forças e lhes impõem uma relação de docilidade-utilidade" (FOUCAULT, 2014, p. 135).

\section{CONSIDERAÇÕES FINAIS?}

No título deste artigo, tomamos de empréstimo trecho de famosa canção do compositor Renato Russo, mas convertemo-la em uma interrogação para causar precisamente a inquietação que mobilizou nossa argumentação. Aparentemente, a disciplina - como entendida pelo senso comum ou tomada aos moldes foucaultianos — é quase diametralmente oposta à liberdade. Ela controla, adestra e estabelece rotinas rigorosas. Porém, no contexto do ensino remoto, quando de sua dissolução, ela é posta em perspectiva comparativa com uma nova forma de controle que, embora possa ser nomeada - pelo menos em princípio - como liberdade, é tão ou mais intensa que o paradigma disciplinar, exatamente porque desobriga os "dominadores" enquanto advoga aos "dominados" a necessidade de um incessante automonitoramento que se retroalimenta e se acirra a partir do sentimento de insuficiência e culpa. Assim, no contexto remoto, a disciplina passa a ser entendida pelos alunos, se não como liberdade, como uma fonte essencial de segurança ontológica que lhes confere conforto e mitiga, ao recalcar, os efeitos das ansiedades existenciais inerentes ao viver. Ao mesmo tempo em que a liberdade instaurada pela dissolução da regulação espaço-temporal da escola logo se mostra aprisionante porque acirra, na sociedade do desempenho, a autocobrança e a exposição aos estímulos externos, conforme logrou mostrar estre trabalho.

\begin{tabular}{|l|l|l|l|l|}
\hline Qovista Q Dialectus & Ano 10 & n. 23 & Maio - Agosto 2021 & p. 231 - 250 \\
\hline
\end{tabular}


Por óbvio, esta análise constitui apenas uma das dimensões do clamor discente pelo retorno dos micropoderes disciplinares, à qual certamente pode-se acrescer, a partir de futuras pesquisas e reflexões, novas variáveis intervenientes neste fenômeno, dentre as quais eu destacaria a própria eficácia dos métodos didáticos adotados pelos professores na esteira das recomendações e limites estruturais a que estão submetidos na modalidade remota de ensino por óbvio, avaliada a partir de critérios objetivos outros que não a percepção subjetiva dos discentes, como feito neste primeiro esforço - e o relevo das redes sociais no contexto do excesso de estímulos externos que, entre outras coisas, recrudesce a autocobrança por desempenho ${ }^{19}$.

Embora o trabalho não se detenha nos pontos supracitados, penso que cumpre o papel de trazer uma importante reflexão à tona que diz respeito não apenas a uma experiência já vivenciada, mas especialmente a um processo em curso - como Byung-Chul Han não se furta de apontar exaustivamente - cujos efeitos seguirão a ser sentidos, mesmo quando a instituição escolar voltar a arregalar seus olhos vigilantes e disciplinadores sobre os estudantes e a experiência de agora, traumática para muitos professores e alunos, soe como um passado de que ser pode abdicar. Longe de intentar fornecer uma solução moral ou didática nos moldes de "um caminho a ser seguido", encerro este texto na direção contrária, indicando os desafios a serem enfrentados doravante: como equacionar as crescentes demandas por liberdades e seus possíveis efeitos colaterais que recaem precisamente naquilo que pretendem atacar? Entre disciplina e desempenho, há uma terceira via possível?

\section{AGRADECIMENTOS}

O diálogo com alunos e alunas do Centro de Ensino Médio Ave Branca (CEMAB), do Centro de Ensino Médio 5 de Taguatinga (CEM 5) e do Centro de Ensino Médio 12 de Ceilândia (CEM 12) foi fundamental para a consecução deste texto. Por isso, agradeço pelos relatos concedidos, pelas trocas cotidianas de conhecimentos, reclamações e questionamentos sobre o futuro. Este texto materializa, em alguma medida, o que construímos juntos ao longo dos anos letivos de 2020 e 2021.

19 A este respeito, vale a leitura da obra A estetização do mundo (LIPOVETSKY; SERROY, 2015) em cujos autores argumentam que o relevo conferido à dimensão imagética da vida — inclusa aí a inegável importante das redes sociais virtuais na contemporaneidade - leva ao fenômeno que dá título ao livro, que caracteriza um mundo que, como nunca, é mediado pelo belo, pelo novo, pelo saudável. Por isso, as pessoas se ocupariam então em formatar suas experiências de modo a torná-las as mais belas possíveis, para que sejam "postáveis", ou melhor, "instagramáveis".

\begin{tabular}{|l|l|l|l|l|}
\hline Qovista Q Dialectus & Ano 10 & n. 23 & Maio - Agosto 2021 & p. 231 - 250 \\
\hline
\end{tabular}




\section{REFERÊNCIAS}

BAUMAN, Zygmunt. 44 cartas do mundo líquido moderno. Rio de Janeiro: Zahar, 2011.

BECK, Ulrich. Sociedade de risco: rumo a uma outra modernidade. 2. ed. São Paulo: Editora 34, 2011.

BOURDIEU, Pierre. Razões práticas: sobre a teoria da ação. 9. ed. Campinas: Papirus, 1996, p. 53-73.

. Los herederos: los estudiantes y la cultura. 2. ed. Buenos Aires: Siglo Veintiuno Editores, 2013

CERTEAU, Michel de. A invenção do cotidiano: 1. artes de fazer. Petrópolis: Vozes, 1994.

DEMO, Pedro; Silva, Renan Antônio da. Efeito desaprendizagem na escola básica. Publicação independente, 2021. Edição Kindle.

DOSTOIÉVSKI, Fiódor. Notas do subsolo. Porto Alegre: L\&PM, 2011. Edição Kindle.

FOUCAULT, Michel. Vigiar e punir: nascimento da prisão. 42. ed. Petrópolis: Vozes, 2014.

GIDDENS, Anthony. Modernidade e identidade. Rio de Janeiro: Zahar, 2002.

. A constituição da sociedade. São Paulo: Editora Martins Fontes, 2003.

HAN, Byung-Chul. Sociedade do cansaço. Petrópolis: Vozes, 2015.

Agonia do eros. Petrópolis: Vozes, 2017a. Edição Kindle.

. Topologia da violência. Petrópolis: Vozes, 2017b. Edição Kindle.

LIPOVETSKY, Gilles; SERROY, Jean. A estetização do mundo: viver na era do capitalismo artista. São Paulo: Companhia das Letras, 2015.

MANN, Thomas. A montanha mágica. São Paulo: Companhia das Letras, 2016. Edição Kindle.

PENSO, Maria Aparecida; SENA, Denise Pereira Alves de. A desesperança do jovem e o suicídio como solução. Sociedade e Estado, UnB, Brasília, v. 35, n. 1, p. 61-81, jan./abr. 2020.

SANTOS, Boaventura de Sousa. A cruel pedagogia do vírus. Coimbra: Almedina, 2020.

SILVA, Renato Izidoro da. Psicanálise e educação: vias para subversão do sujeito. Inter-Ação, UFG, Goiânia, v. 32, n. 1, p. 127-157, jan./jun. 2007.

SIMMEL, Georg. A metrópole e a vida mental. In: VELHO, Otávio Guilherme (Org.). O fenômeno urbano. Rio de Janeiro: Zahar Editores, 1967.

\begin{tabular}{|l|l|l|l|l|}
\hline Govista Q Dialectus & Ano 10 & n. 23 & Maio - Agosto 2021 & p. 231 - 250 \\
\hline
\end{tabular}

